\title{
Vocal Parameters That Indicate Threat Level Correlate with FOS Immunolabeling in Social and Vocal Control Brain Regions
}

\author{
Jesse M.S. Ellis Lauren V. Riters \\ Department of Zoology, University of Wisconsin, Madison, Wisc., USA
}

\section{Key Words}

Lateral septum • Medial preoptic area · Alarm call •

Anti-predator display $\cdot$ Black-capped chickadee

\begin{abstract}
Transmitting information via communicative signals is integral to interacting with conspecifics, and some species achieve this task by varying vocalizations to reflect context. Although signal variation is critical to social interactions, the underlying neural control has not been studied. In response to a predator, black-capped chickadees (Poecile atricapilla) produce mobbing calls (chick-a-dee calls) with various parameters, some of which convey information about the threat stimulus. We predicted that vocal parameters indicative of threat would be associated with distinct patterns of neuronal activity within brain areas involved in social behavior and those involved in the sensorimotor control of vocal production. To test this prediction, we measured the syntax and structural aspects of chick-a-dee call production in response to a hawk model and assessed the protein product of the immediate early gene FOS in brain regions implicated in context-specific vocal and social behavior. These regions include the medial preoptic area (POM) and lateral septum (LS), as well as regions involved in vocal motor control, including the dorsomedial nucleus of the intercollicular complex and the HVC. We found correlations linking call rate
\end{abstract}

(previously demonstrated to reflect threat) to labeling in the POM and LS. Labeling in the HVC correlated with the number of $D$ notes per call, which may also signal threat level. Labeling in the call control region dorsomedial nucleus was associated with the structure of $D$ notes and the overall number of notes, but not call rate or type of notes produced. These results suggest that the POM and LS may influence attributes of vocalizations produced in response to predators and that the brain region implicated in song control, the HVC, also influences call production. Because variation in chick-a-dee call rate indicates predator threat, we speculate that these areas could integrate with motor control regions to imbue mobbing signals with additional information about threat level.

Copyright $\odot 2011$ S. Karger AG, Basel

\section{Introduction}

Transmitting information to conspecifics is an integral part of vertebrate social behavior [Bradbury and Vehrencamp, 1998]. Interacting with conspecifics, be they offspring, rivals or mates, requires communication. Accordingly, many species use a variety of signals, especially vocalizations, in different social contexts [Marler, 2004a, b]. Different signals have different meanings for receivers [e.g. Manser et al., 2001], but, even within signal

\section{KARGER}

(c) 2011 S. Karger AG, Basel

Fax +41613061234 E-Mail karger@karger.ch www.karger.com www.karger.com/bbe
Dr. Jesse Ellis

Department of Zoology, University of Wisconsin

426 Birge Hall

Madison, WI 53709 (USA)

Tel. +1 206406 7776, E-Mail jmellis2@ wisc.edu 
types, variation in production can transmit useful information, adding to or altering the meaning of the signal [Vehrencamp, 2000; Illes et al., 2006; Ellis, 2008; RiveraGutierrez et al., 2010]. The neural correlates underlying signal variation have been studied in a few cases, but determining how the brain creates variation within a signal type is needed as a first step to understanding the neural basis of communication.

To identify patterns of neuronal activity associated with variation in vocal behavior, it is useful to study a system in which variation in acoustic structure has been established. Bird calls are generally relatively short, simple vocalizations, but some calls vary considerably even within a single functional type [Marler, 1967]. One context in which the neural basis of vocal variation can be easily addressed, and which has been well studied behaviorally, is during predator encounters. When animals encounter predators, they often take evasive action, but may also produce signals [Curio, 1978; Caro, 2005]. Such signals can vary amongst individuals and signal production may depend on the social context and the predator context. Some species only produce alarms and mobbing signals if offspring or potential mates are present (e.g. jays, babblers and sciurids) [Sherman, 1977; Maklakov, 2002; Griesser and Ekman, 2005]. Some species encode the nature of the threat (aerial, terrestrial) with different signals (e.g. monkeys and meerkats) [Cheney and Seyfarth, 1985; Zuberbühler, 2000; Manser, 2001; Zuberbühler, 2001]. Others use variation within a signal to communicate the danger a predator presents (e.g. tits, reed warblers) [Baker and Becker, 2002; Welbergen and Davies, 2008; Courter and Ritchison, 2010].

Black-capped chickadees use one of the most flexible call systems known in animals, the eponymous chick- $a$ dee call [Hailman et al., 1985; Hailman and Ficken, 1986; Hailman et al., 1987]. The calls are used as mobbing signals, given after an individual has initially detected a predator and approached it [Smith, 1991]. The chick-a-dee call has 4 distinct note types, designated A-D. Notes always occur in the general order A-B-C-D [Hailman and Ficken, 1986; Hailman et al., 1987]. Despite this level of structure, individuals can change the number of each note type to produce a wide range of utterances [Hailman et al., 1985]. Parameters of each note type, especially D notes, can also be adjusted. Some variation appears to be meaningful. Differences in a number of parameters reflect the threat level a chickadee perceives from a particular predator. For example, chickadees call more in response to smaller, high-threat predators, and use more D notes [Baker and Becker, 2002; Templeton et al., 2005].
The ratio of $\mathrm{A}$ to $\mathrm{B}$ notes and the energy dispersion in $\mathrm{D}$ notes also change depending on the threat presented [Baker and Becker, 2002; Templeton et al., 2005]. However, even within the context of a single threat, call parameters can vary greatly from individual to individual [Baker and Becker, 2002; Templeton et al., 2005]. We took advantage of the known variation in the call structure of chickadees and their ability to elicit calls, in order to examine neural correlates of signal variation as a first step in identifying how a meaningful variation in calls is produced.

In songbirds (passerines) such as chickadees, vocal motor control and learning circuits have been relatively well studied [Wild, 2004; Brenowitz and Beecher, 2005; Mooney, 2009], but how the brain integrates internal and social information with vocal motor output to moderate signal production is not clear. Vocal output, like any motor activity, occurs in a wide range of functional contexts [Marler, 2004b]. Therefore, it is likely that a number of functionally distinct neural systems (e.g. social, sexual and anti-predator) must integrate information to control vocal output [Newman, 1999; Goodson, 2005]. The dorsomedial nucleus of the intercollicular complex (DM) is thought to be the primary region controlling call output [Brown, 1965a; Wild et al., 1997; Fukushima and Aoki, 2000; Dubbeldam and den Boer-Visser, 2002]. Electrical stimulation of the DM results in the production of calls in a number of species, in both passerines and nonpasserines [Brown, 1971, 1973; Seller, 1981]. Lesions of this area result in apparent muteness [Brown, 1965b; Seller, 1980; Fukushima and Aoki, 2000]. In a detailed study of red-winged blackbirds (Agelaius phoeniceus), electrical stimulation of DM triggered calls of relatively invariant structure [Brown, 1971]. In contrast, electrical stimulation of diencephalic areas, including portions of the lateral septum (LS) and medial preoptic nucleus (POM), elicited several types of highly variable vocalizations including alarm calls [Brown, 1971]. Both the LS and POM integrate internal and external environmental information [Hull et al., 1999; Dobson et al., 2003; Goodson et al., 2005]. These regions have been implicated in a range of social behaviors, including agonistic and defensive behavior [Goodson, 1998; Goodson et al., 1999; Gammie, 2005; Alger and Riters, 2006; Heimovics and Riters, 2006; Riters, 2006; Heimovics and Riters, 2007; Alger et al., 2009]. The LS and POM have also been implicated in birdsong, with relationships between markers in these regions and songs differing, depending upon the social context in which a bird is singing [Goodson, 1998; Goodson et al., 1999; Alger and Riters, 2006; Heimovics and 
Riters, 2006, 2007; Alger et al., 2009]. The POM and LS are reciprocally neuroanatomically connected [Riters and Alger, 2004] and the POM projects to the DM [Montagnese et al., 2004; Riters and Alger, 2004], suggesting a candidate neural circuit for the regulation of variation in the production of threat signals (fig. 1).

While regions such as the LS and POM may provide information about the social environment to the DM, variation in call structure may also be regulated by interactions between the DM and the song control system. The song control system is unique to songbirds and consists of a specialized group of interconnected brain regions devoted to sensorimotor processing and song production [Ziegler and Marler, 2008]. A number of studies, however, indicate that the role of the song system may extend to calling behavior, particularly the production of the learned components of calls [Simpson and Vicario, 1990; Fukushima and Aoki, 2000, 2002; Liu et al., 2009]. Specifically the song control region, the HVC, projects to the robust nucleus of the arcopallium (RA) which projects to the $\mathrm{DM}$ as well as to respiratory and syringeal premotor neurons [Wild, 1997] (fig. 1). In estrildid finches, males produce contact calls that carry an individually distinctive signature. Lesions of either the HVC or RA of the song control system result in the loss of this signature, such that these calls revert to female-like calls lacking individual specificity [Simpson and Vicario, 1990; Vicario and Simpson, 1995; Fukushima and Aoki, 2000; Vicario, 2004]. Beyond this, the role of song control nuclei in call production is unknown.

Our goal was to gain an understanding of the neural variation that underlies individual vocal variation within a single context. We hypothesized that a number of brain regions that are active in social encounters and vocal production may be active when producing predator-elicited mobbing calls in chickadees and that variation in regional activity might relate to variation in call structure and production among individuals. In particular, we examined call parameters known to represent a threat to the receivers [Baker and Becker, 2002; Templeton et al., 2005]. Here we used immunolabeling for FOS, an immediate early gene as an indirect marker of neuronal activity to identify patterns of activity in the POM, LS, DM, HVC and RA in association with variations in alarm call production. We additionally measured FOS immunolabeling in the ventral tegmental area (VTA) and midbrain central gray $(\mathrm{GCt})$, which send projections to the POM and song control regions [Appeltants et al., 2000; Appeltants et al., 2002; Ball et al., 2003; Riters and Alger, 2004; Person et al., 2008] (fig. 1) and have been implicated in

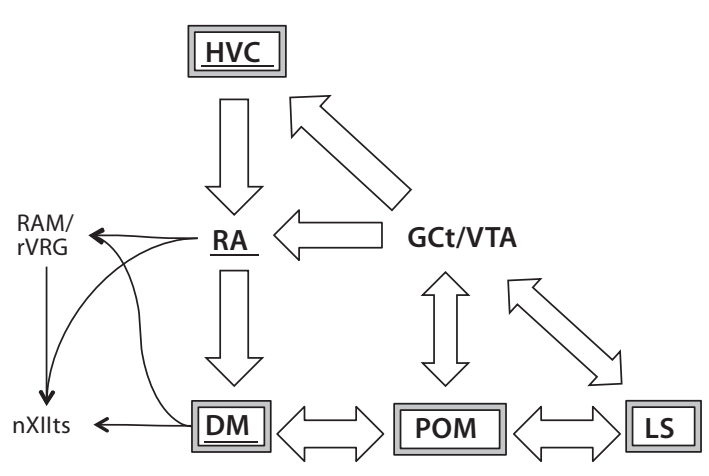

Fig. 1. Known neuroanatomical connections between the vocal control and social behavior regions examined in this study. Double-headed arrows represent reciprocal projections. Boxes indicate regions where FOS activity correlated with call measures. Vocal control regions are underlined, social behavior regions are not. Motor control regions (nXIIts = 12th cranial nerve; $\mathrm{RAM}=$ nucleus retraoambigualis; $\mathrm{rVRG}=$ rostral ventral respiratory group) were not examined.

motivation [Heimovics and Riters, 2005; Hara et al., 2007; Huang and Hessler, 2008; Lynch et al., 2008; Woods et al., 2010] and song production [Maney and Ball, 2003; Alger et al., 2009; Goodson et al., 2009; Heimovics et al., 2009].

\section{Materials and Methods}

\section{Animals}

Twelve black-capped chickadees were caught with mist nets and potter traps at sites within 22 miles of Madison, Wisc. in late 2009 and early 2010, prior to the breeding season. Six females and 6 males were housed with other chickadees (from a different study) in mixed-sex groups of up to 6 individuals in outdoor aviaries $(3.5 \times 3.5 \times 2.75 \mathrm{~m}$; i.e. on natural photoperiod $)$ at the University of Wisconsin-Madison. The sex of the subjects was determined via the gonads when they were killed for brain collection.

\section{Vocal Elicitation and Stimulus Presentation}

A taxidermic model of a Cooper's hawk (Accipiter cooperii) in a perched posture was borrowed from the Wisconsin University Zoological Museum. To elicit vocalizations in chickadees, the model was placed on a 1-meter-high platform in an empty aviary, visually isolated from the chickadees and concealed with a cardboard box. A Sennheiser ME64 cardioid microphone with a K6 powering module, directed up and into the aviary, recorded from near one edge of the aviary approximately $30 \mathrm{~cm}$ off the ground. It recorded onto a Marantz PMD 660 recorder at $48-\mathrm{kHz}$ sample rate and 16-bit depth. The test subject was introduced to the aviary; an observer entered a blind fitted with 1-way glass and began recording behavior by observation and all the vocalizations with the recorder. Subjects were given at least $5 \mathrm{~min}$ to become accus- 
Fig. 2. Spectrogram of the chick-a-dee call. Darker tones show higher amplitude. Calls produced in response to the Cooper's hawk contained $\mathrm{A}$ notes and $\mathrm{D}$ notes. A notes were tonal and frequency-modulated. D notes were noisy and consisted of a fundamental (the darkest band) and a number of side bands.

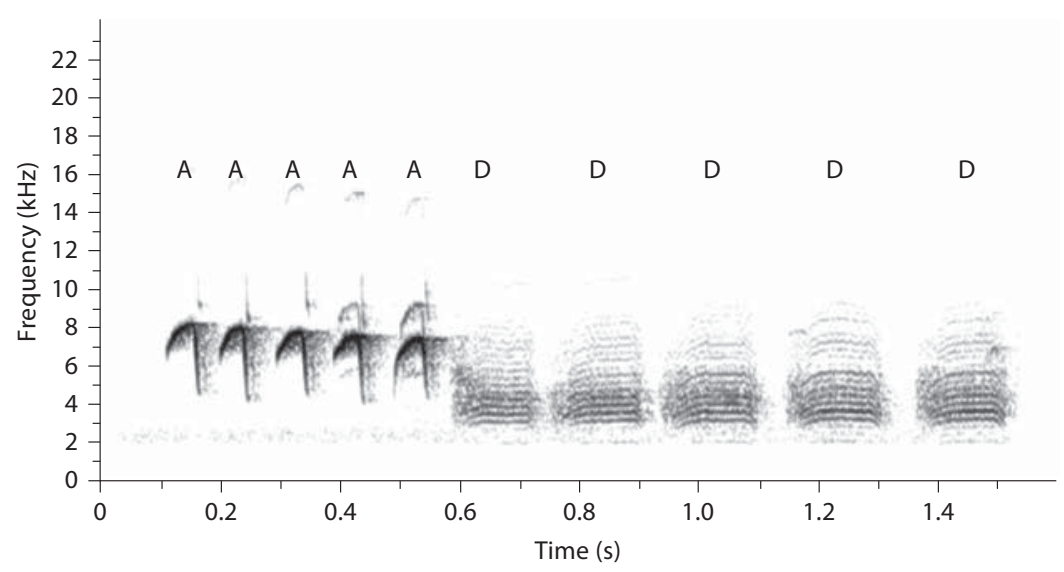

night at room temperature. This antibody was previously validated in starlings in our laboratory [Alger et al., 2009]. A 30-min PBS-T rinse followed, then tissue was incubated in secondary antibody solution [2\% NGS with biotinylated goat anti-rabbit (1:250)]. Tissue was again rinsed in PBS-T and then incubated in $\mathrm{AB}$ solution for $60 \mathrm{~min}$. The avidin-biotin complex was visualized by a 7 -min treatment with diaminobenzadine. Sections were mounted on gel-coated slides and coverslipped after dehydration.

\section{Sound Analysis}

Sounds were analyzed with Raven 1.4 (Bioacoustics Research Program, Cornell Laboratory of Ornithology, Ithaca, N.Y., USA), and calls were delineated and classified without knowledge of the results of FOS immunocytochemistry for each individual. Notes were classified by eye according to type (A, B, C or D; fig. 2) using the criteria given by Hailman et al. [1985] and the following measures were calculated: peak frequency of D notes and A notes and D-note duration, entropy (a measure of noisiness or energy distribution) and bandwidth (using 5 and $95 \%$ frequency cutoffs). B and $\mathrm{C}$ notes were not measured because none were produced (as defined and illustrated by Ficken et al. [1978] and illustrated by Sturdy et al. [2000]). Three measures were calculated from each call as a unit: the number of D notes and A notes and the total of notes per call. The number of chick-a-dee calls given over the 10min observation period was also noted.

\section{FOS Labeling Quantification}

FOS-immunoreactive cells were counted on a Nikon microscope with a Spot camera (Diagnostics Instruments, Inc.) and MetaVue software (Universal Imaging Corp.). Cell counts were made in a box or oval centered on each area of interest (fig. 3). Boundaries were set within the area of interest across all sections. Each area was sampled on both sides of the midline, and 3 sections were examined, producing 6 measures per subject, which were averaged. In cases of tissue damage, the count was dropped and the average calculated from the remaining section areas. MetaVue uses a threshold value for measurement inclusion based on the grayscale values of the 8-bit photomicrograph. The threshold was set such that it included labeled cells; this was agreed upon by 2 


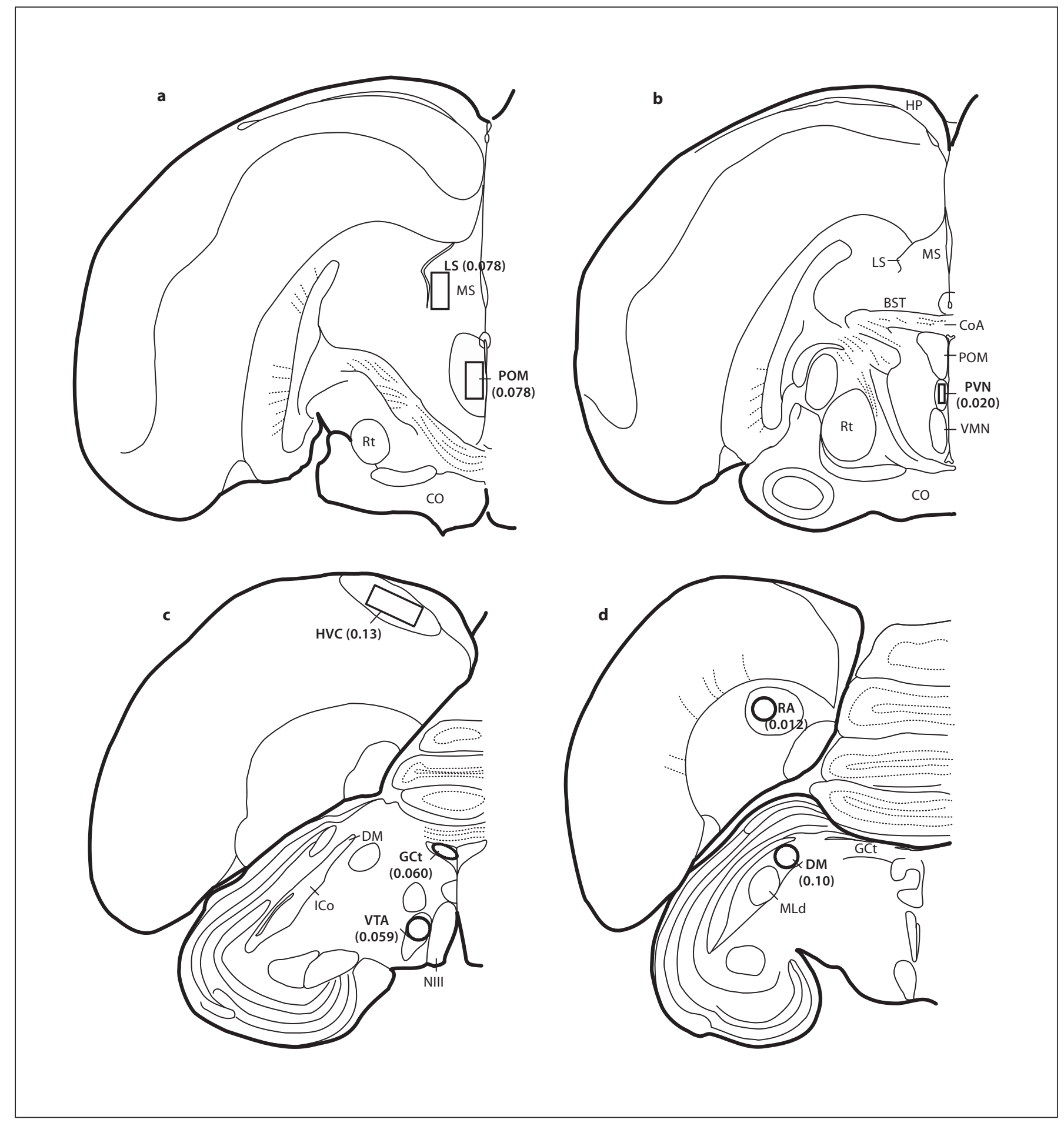

Fig. 3. Brain regions of interest and areas of FOS-immunolabeling measurement. Measurement region areas $\left(\mathrm{mm}^{2}\right)$ are indicated in parentheses. BST $=$ Bed nucleus of the stria terminalis; $\mathrm{CO}=$ optic chiasm; CoA $=$ anterior commissure; HP = hippocampus; ICo = intercollicular complex; MLd = nucleus mesencephalicus lateralis pars dorsalis; $\mathrm{MS}=$ medial septum; $\mathrm{NIII}=$ oculomotor nerve; $\mathrm{Rt}=$ nucleus rotundus; $\mathrm{VMN}=$ ventromedial nucleus of the hypothalamus. 
independent observers. The same threshold was used for each region for all subjects, but each measurement was visually checked to confirm that extraneous noncellular areas were compensated for.

\section{A Note on the Intercollicularis}

The intercollicularis has proven to be a complex, heterogeneous area, and despite a thorough review [Puelles et al., 1994], many authors are not always clear about precisely which subregions are being analyzed. Here, we explicitly examined the area termed the intercolliculus core by Puelles et al. [1994], which controls call production in birds. We refer to this area as DM throughout the paper, consistent with other more recent studies.

\section{Statistics}

All statistics were run with R (R-foundation: http://www.rproject.org). Assumptions of parametric statistics were checked via normal-quantile plots and variables transformed as noted (see Results). One multiple linear regression for each behavior or call attribute was used to assess whether the sex of a subject and the counts of FOS immunoreactive cells in selected brain regions explained behaviors and the physical attributes of chick-a-dee calls. Backward stepwise regression was used to eliminate brain regions that did not contribute significantly to the model; forward-stepwise regression was used to confirm the backward regression. Significance values were corrected using sequential Bonferroni procedures, although all $\mathrm{p}$ values $<0.05$ are reported for readers who prefer to assess significance without the overly stringent Bonferroni corrections [Moran, 2003; Nakagawa, 2004].

\section{Results}

\section{General Behavior}

Chickadees did not produce any chick-a-dee calls during the $5 \mathrm{~min}$ prior to the presentation of the hawk model, and generally performed low levels of maintenance behavior, such as feeding, eating and preening. They became more active in response to the hawk model. They changed perches in a mean of $81 \%(+6 \%$ SEM) of the fifteen 10 -second flight periods monitored in each raptor presentation, significantly more than the $46 \%$ ( $\pm 21 \%)$ observed before the raptor was present (paired t test, 2 -tailed, percent flights before and during: $\mathrm{t}=3.99$, d.f. $=$ $11, \mathrm{p}=0.002)$. They rarely fed (3/12 subjects), drank $(1 / 12)$, preened $(0 / 12)$ or bill-wiped $(0 / 12)$ when the hawk model was present. The proportion of periods with movement did not correlate with numbers of FOS-labeled cells in any brain region, and no differences were identified between birds that fed or drank and those that did not.

\section{Vocal Behavior}

Ten of 12 individuals gave chick-a-dee calls in response to the hawk model (online supplementary figure
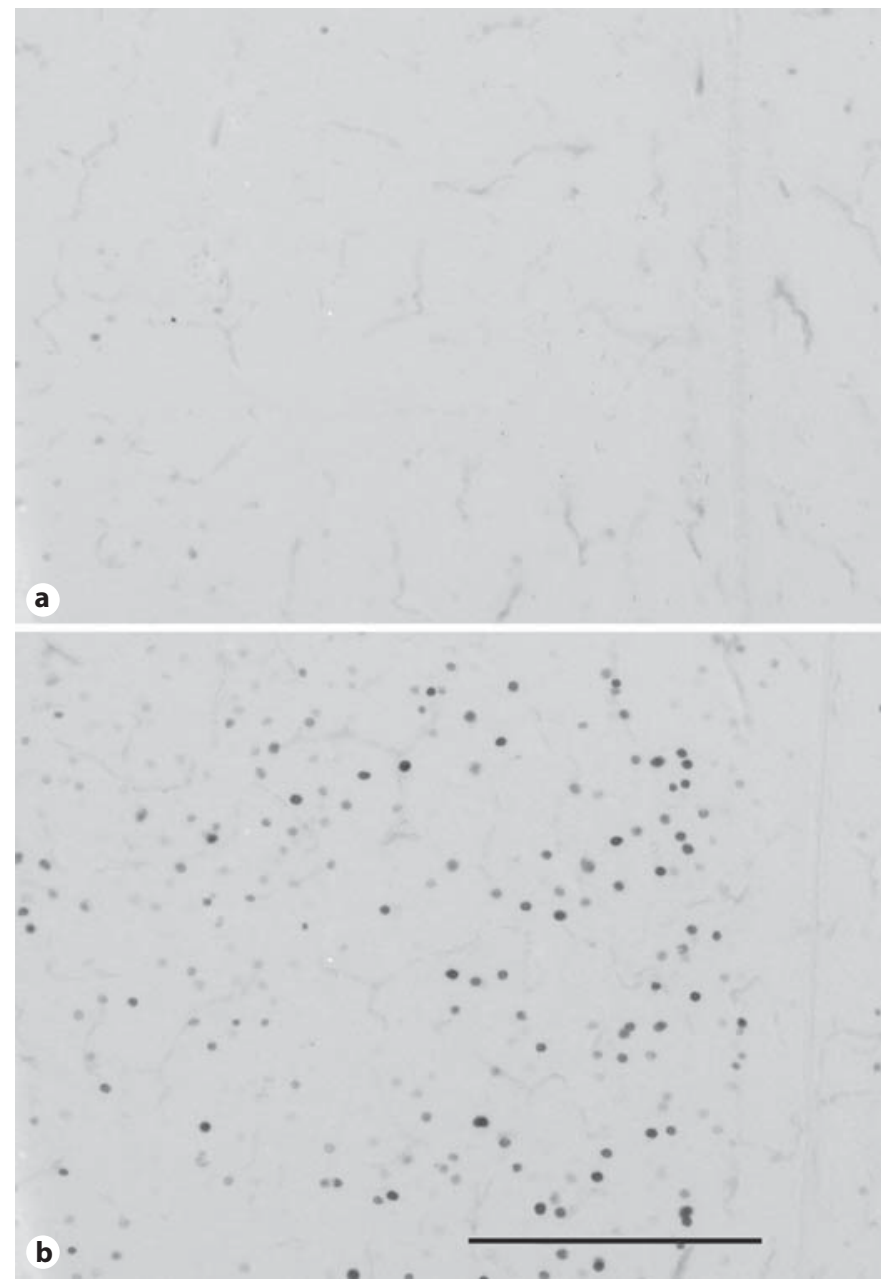

Fig. 4. FOS immunolabeling in the POM of black-capped chickadees. $\times 200$. The ventricle appears as a line paralleling the right side. Black bar: $150 \mu \mathrm{m}$. a An individual that called at a low rate. b An individual that called at a high rate.

S1; for all online supplementary material, see www. karger.com/doi/10.1159/000334078). Subjects did not produce B or C notes as defined by Hailman et al. [1985]. Chickadees that called produced an average of $3.8 \pm 0.44$ D notes per call.

\section{Relationships between Vocal Behavior and Number of FOS-Labeled Cells}

Stepwise multiple regression analyses were run to examine the relationships between the numbers of FOS-immunolabeled cells in each brain region measured, sex and each call measure. Several transformations were required: number of chick-a-dee calls was $\log (\mathrm{x}+1)$-transformed and FOS-immunolabeling counts in the VTA, POM and 
Table 1. Relationships between FOS labeling and call parameters

\begin{tabular}{|c|c|c|c|c|c|c|c|c|}
\hline Measure & Region & B & $\begin{array}{l} \pm \text { Std. } \\
\text { error }\end{array}$ & $\beta$ & $\mathrm{t}$ value & $\mathrm{p}$ value & $\begin{array}{l}\text { Bonferroni } \\
\text {-adj. } \alpha\end{array}$ & Sig. \\
\hline \multicolumn{9}{|c|}{$\ln$ (number of chick-a-dee calls); mean \pm SE: $1.2 \pm 0.8$} \\
\hline \multirow[t]{2}{*}{ Adj $R^{2} 0.59, p=0.0071, n=12$} & $\ln (\mathrm{POM})$ & 2.71 & 0.69 & 0.88 & 3.91 & 0.0035 & 0.025 & ** \\
\hline & LS & -0.061 & 0.018 & -0.77 & -3.41 & 0.0077 & 0.05 & ** \\
\hline \multicolumn{9}{|l|}{ D-note entropy: $3.15 \pm 0.14$} \\
\hline \multirow[t]{2}{*}{ Adj $R^{2} 0.57, p=0.021, n=10$} & $\mathrm{DM}$ & 0.011 & 0.0031 & 1.21 & 3.70 & 0.0076 & 0.025 & ** \\
\hline & $\ln (\mathrm{POM})$ & -0.42 & 0.17 & 0.80 & -2.44 & 0.045 & 0.05 & * \\
\hline \multicolumn{9}{|c|}{ D-note peak frequency $(\mathrm{Hz}): 3,570 \pm 140$} \\
\hline \multirow[t]{4}{*}{ Adj $\mathrm{R}^{2} 0.91, \mathrm{p}=0.0020, \mathrm{n}=10$} & $\ln (\mathrm{HVC})$ & 72 & 9.7 & 0.88 & 7.44 & 0.0007 & 0.0125 & *** \\
\hline & $\ln (\mathrm{POM})$ & 621 & 88 & 1.17 & 7.07 & 0.0009 & 0.0167 & $* * *$ \\
\hline & PVN & -48.6 & 12.5 & -0.53 & -3.88 & 0.012 & 0.025 & * \\
\hline & $\mathrm{DM}$ & -5.7 & 1.9 & -0.60 & -3.06 & 0.028 & 0.05 & * \\
\hline \multicolumn{9}{|l|}{ Mean D notes/call: $3.5 \pm 1.8$} \\
\hline \multirow[t]{2}{*}{ Adj $\mathrm{R}^{2}=0.83, \mathrm{p}=0.00084, \mathrm{n}=10$} & $\ln (\mathrm{HVC})$ & 0.57 & 0.17 & 0.69 & 3.42 & 0.011 & 0.025 & * \\
\hline & Sex & 1.47 & 0.55 & & 2.7 & 0.031 & 0.05 & * \\
\hline \multicolumn{9}{|l|}{ Mean total notes/call: $6.6 \pm 1.6$} \\
\hline \multirow[t]{4}{*}{ Adj $R^{2}=0.63, p=0.012, n=10$} & Sex & 1.91 & 0.43 & - & 4.43 & 0.0069 & 0.0125 & ** \\
\hline & LS & -0.097 & 0.028 & -0.59 & -3.50 & 0.017 & 0.0167 & NS \\
\hline & $\ln (\mathrm{POM})$ & -3.83 & 1.38 & -0.62 & -2.78 & 0.039 & 0.025 & NS \\
\hline & $\mathrm{DM}$ & 0.059 & 0.022 & 0.53 & 2.63 & 0.047 & 0.05 & * \\
\hline \multicolumn{9}{|c|}{ Bandwidth of D notes $(\mathrm{Hz}): 1,990 \pm 340$} \\
\hline Adj $\mathrm{R}^{2}=0.42, \mathrm{p}=0.025, \mathrm{n}=10$ & $\mathrm{DM}$ & 16.3 & 5.9 & 0.70 & 2.76 & 0.025 & - & * \\
\hline
\end{tabular}

p value: adj. alpha ${ }^{*}>0.3 ;{ }^{* *}<0.3,>0.1 ; * * * 0.1$.

HVC were log transformed to meet parametric statistical requirements. RA labeling was nearly undetectable, with only 1 individual showing 3 cells with FOS immunolabeling. This region was therefore excluded from further analysis. The sex of the subject and the average numbers of FOS-immunolabeled cells in each measurement area (population mean \pm SEM, $\mathrm{n}=12$; fig. 3$)$ in the $\operatorname{HVC}(9.8$ $\pm 10), \mathrm{DM}(19 \pm 13), \mathrm{POM}(6.3 \pm 4.3), \mathrm{LS}(24 \pm 2.8)$, paraventricular nucleus (PVN, $2.9 \pm 2.0)$, VTA (5.1 \pm $5.4)$ and GCt $(22 \pm 13)$ were entered as independent variables into separate backward-stepwise regression models for each of the following dependent variables: the number of chick-a-dee calls, the mean number of $\mathrm{D}$ notes and $\mathrm{A}$ notes per call, the mean D-note duration, peak frequency, entropy and bandwidth, as well as the mean total number of notes/call (see details below).

Previous work on song has demonstrated that the number or duration of vocalizations may be predicted by the number of labeled cells in song control regions and social brain regions [Maney and Ball, 2003; Riters et al., 2004; Heimovics and Riters, 2005], so we assessed how the independent variables predicted the number of calls produced in the observation period, the mean total number of notes per call and the mean number of $\mathrm{D}$ notes and A notes per call. FOS immunolabeling in the POM and LS together predicted the number of calls a chickadee produced (table 1; fig. 4, 5a). Chickadees that called more tended to have fewer labeled cells in the LS and more labeled cells in the POM.

After statistically accounting for the numbers of labeled cells in the LS, POM and DM, a significant sex difference was identified, with males tending to produce more notes than females (table 1), with the LS and the POM contributing negatively to notes per call and the DM relating positively (table 1, online suppl. fig. S2). After sequential Bonferroni correction, only sex and DM proved to significantly relate to the total number of notes used in a chick-a-dee call.

D-note production related to HVC labeling and the sex of the caller. For a given level of HVC labeling, males produced more $\mathrm{D}$ notes per call, and after including the sex in the model, individuals with higher levels of HVC 
Fig. 5. Partial residual plots to illustrate the relationships of the LS, POM and DM to call parameters after accounting for other independent variables in the model. a Chick-a-dee call rate and number of FOS-labeled cells in the LS and POM. The relationship $\ln$ (total number of calls) = $2.71^{*} \ln (\mathrm{POM})-0.061^{*} \mathrm{LS}+0.81$ describes slopes for both lines. Both LS and POM labeling measures were required in the model to discern significant relationships. b D-note entropy plotted as a function of FOS-labeled cells in the POM and DM. The relationship D-note entropy $=0.011^{*}$ $\mathrm{DM}-0.42^{*} \ln (\mathrm{POM})+3.23$ describes slopes for both lines. D-note entropy increased with increased FOS labeling in the $\mathrm{DM}$, after accounting for the effect of FOS labeling in the POM.

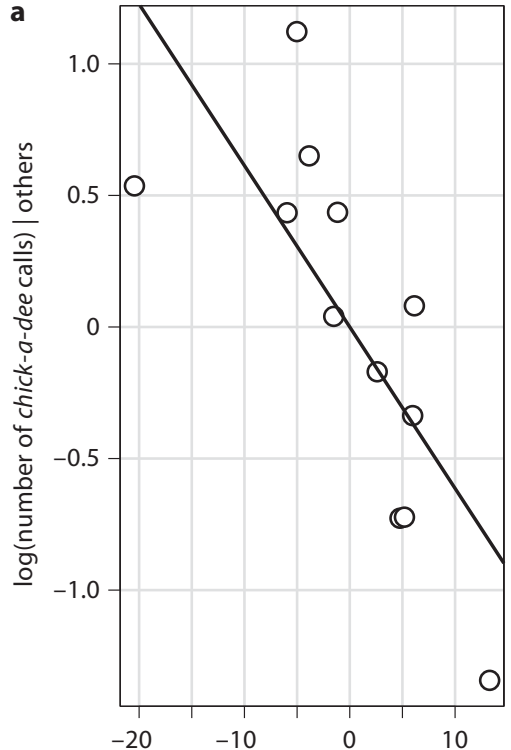

Number of labeled cells in LS $\mid$ others
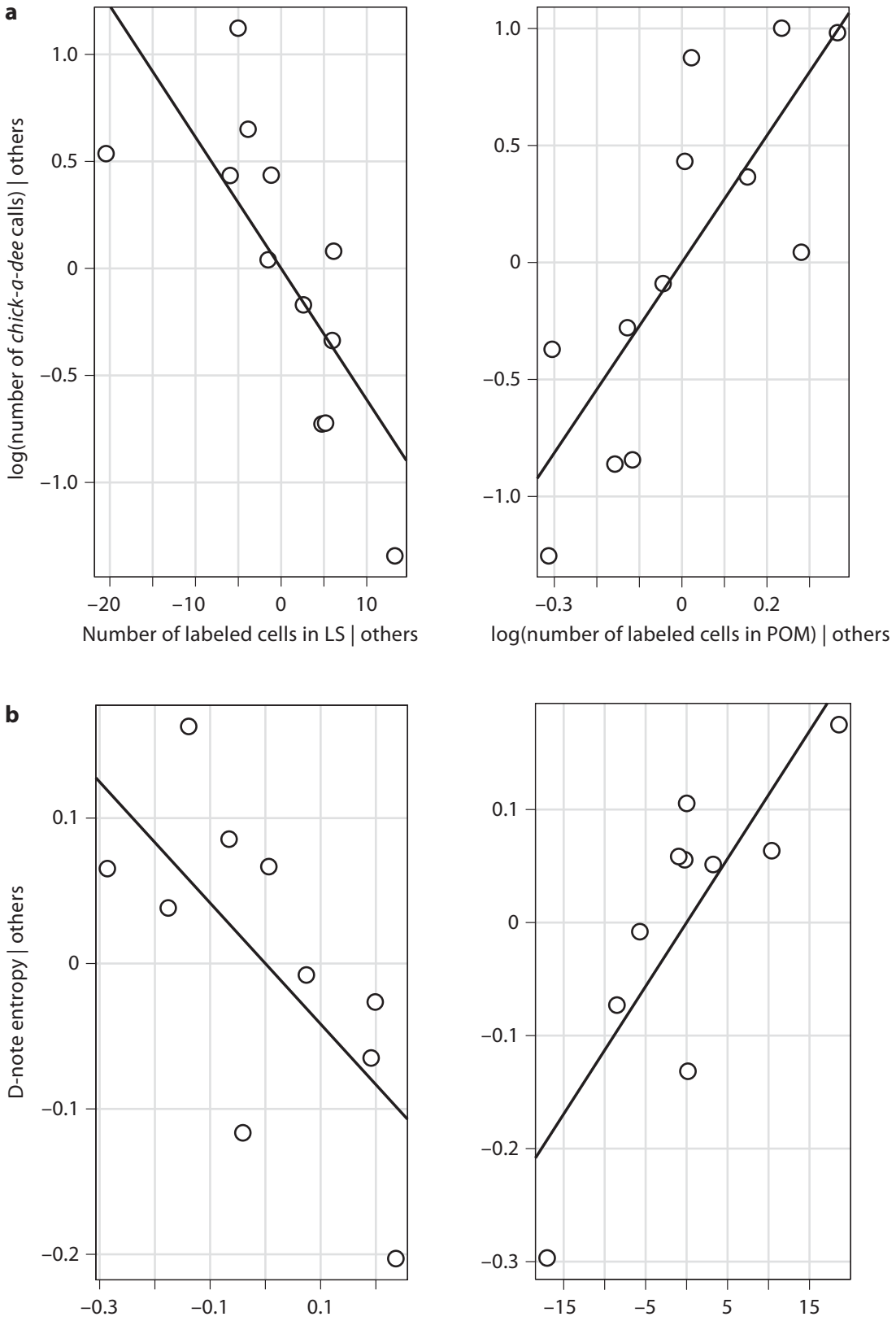

$\log$ (number of labeled cells in POM) | others

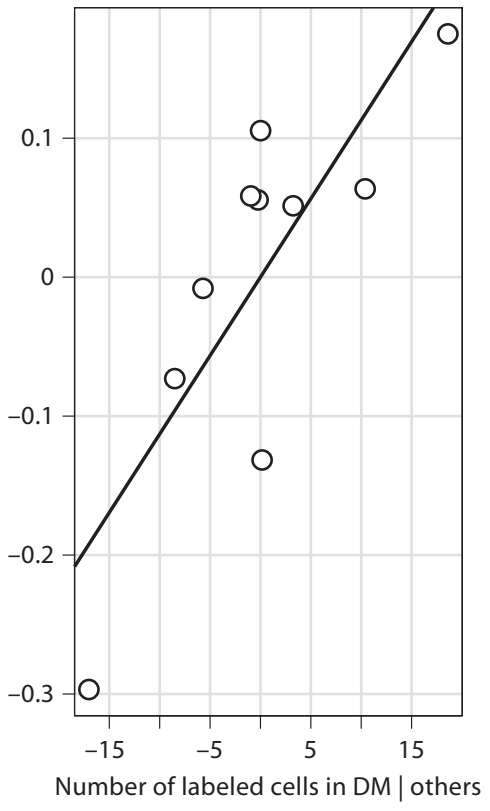

labeling tended to produce more $\mathrm{D}$ notes (table 1; fig. 6). No independent variables (even before Bonferroni correction) predicted the number of A notes per call or the mean D-note duration.

The structure of $\mathrm{D}$ notes has also been thought to relate to the predator threat level [Templeton et al., 2005], so we examined how $\mathrm{D}$-note peak frequency, bandwidth, entropy and duration related to the independent variables. The number of labeled cells in the POM and DM predicted entropy (noisiness) of $\mathrm{D}$ notes across individuals (fig. 5b). For a given level of labeling in the DM, individuals with lower POM labeling tended to have higher D-note entropy; for a given level of POM labeling, individuals with higher DM labeling produced D notes with 


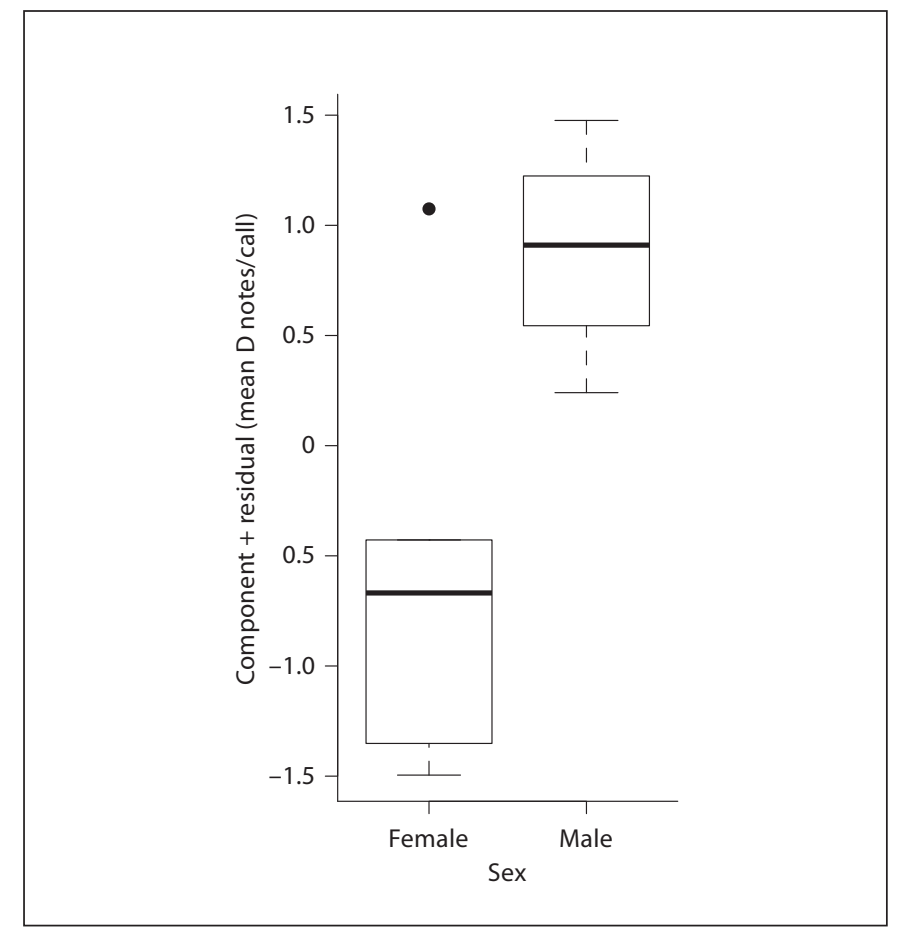

Fig. 6. Caller sex correlates with the number of notes in a chick-adee call. Partial residual box plot of relationship between sex and the total notes produced per chick-a-dee call. Males produced significantly more notes per call. Whiskers are maximum or minimum points within, $1.5 \times$ the interquartile range (IQR); boxes represent the IQR; heavy lines are the median; the dot is an outlier. Males produced significantly more D notes per call.

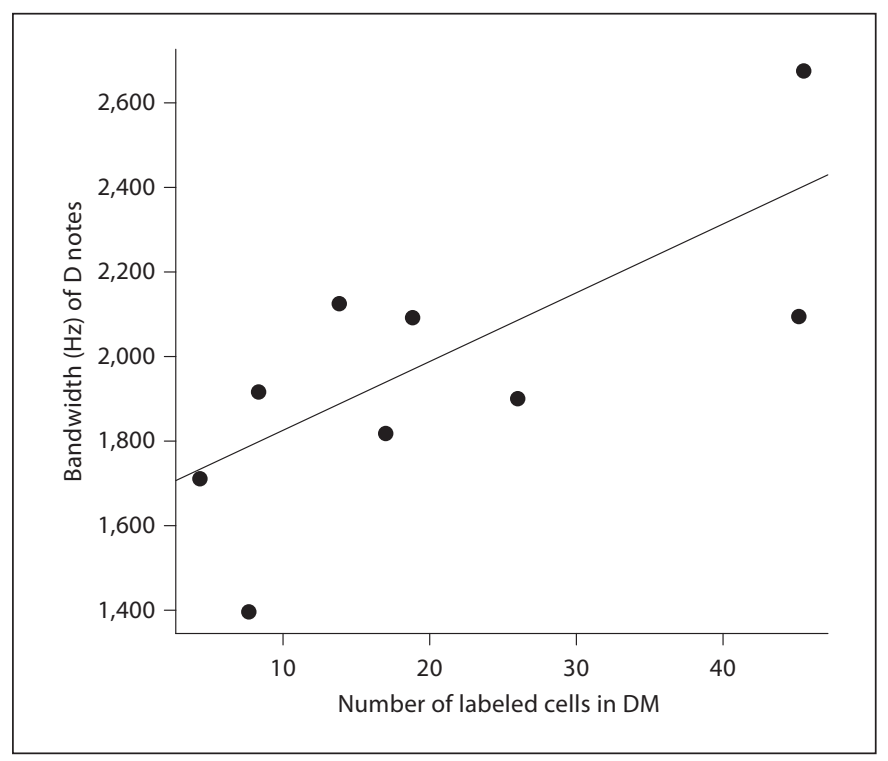

Fig. 7. Relationship between FOS labeling in the DM and bandwidth $(\mathrm{Hz})$ of D notes. Bandwidth of D notes $=16.27^{*} \mathrm{DM}+1,662$. higher entropy. Labeling in the HVC and POM correlated positively to mean $\mathrm{D}$-note peak frequency, while the DM and PVN showed negative correlations (table 1), with the $\mathrm{HVC}$ and POM explaining the most variance in peak frequency. Labeling in the DM predicted the bandwidth of D notes (fig. 7). None of the independent variables related to the duration of $\mathrm{D}$ notes.

\section{Discussion}

This study yielded two results important for understanding the neural control of vocal variation in birds. First, FOS labeling in those areas involved in motivation and social behavior, specifically the POM and LS, showed relationships with a call measure that had previously been shown to communicate threat level. Second, we found FOS labeling in regions involved in both call control (the DM) and song production (the HVC) relate to some parameters of chick-a-dee calls. Together, these data point to a system by which brain regions involved in controlling social motivation might influence vocal output. The chickadee alarm call system, therefore, may prove a useful tool for understanding how regions processing contextual information successfully influence and/or control motor behaviors.

The Role of Social Brain Regions in Chick-a-Dee Call Production

Distinct Patterns of FOS Labeling in the POM and

LS Relate to the Call Rate

We found that labeling in both the POM and LS correlated with the number of calls produced in response to a single predator model. FOS immunolabeling in the LS and POM related to calling rate, but interestingly, statistical assessment of both regions was required to predict call rate. Increased POM labeling was associated with higher call rates, but only after accounting for labeling in LS, and call rates decreased with increased LS labeling for a given POM-labeling level. The statistical effect suggests that both regions influence vocal output, in a complex fashion, and that activity in both areas should be assessed to ascertain relationships with vocal output. This possibility should be examined in other studies and tested experimentally. The two regions are directly linked neuroanatomically and are directly (POM to DM) and indirectly (LS to GCt to the song control system) linked to vocal control regions, so that the nature of their influence on vocal output could be either through links to each other or to vocal control regions. 
FOS Labeling in the POM and PVN Also Relates to D-Note Structure

Correlations of FOS labeling in the POM (with entropy and peak frequency) and in the PVN (with peak frequency) suggest that these regions influence overall note structure. Other measures similar to entropy have been proposed to change with threat level [Templeton et al., 2005]. Peak frequency has not been directly associated with threat level, but the PVN in songbirds is associated with anxiety and stress [Day et al., 2004; Herman et al., 2005], as well as responses to aggressive challenge [Goodson and Evans, 2004]. Further work should examine how activity in both the POM and PVN relate to entropy and peak frequency in social versus predator contexts. Interestingly, 2 other social brain regions, the GCt and VTA, which have been linked to vocal production and motivation [Maney and Ball, 2003; Heimovics and Riters, 2005], showed no links to any call measures in response to a predator, though FOS-labeled cells were visible in both regions.

\section{The Role of Vocal Control Regions in Chick-a-Dee} Call Production

A relatively neglected topic in understanding bird communication is the integration of brain regions implicated in calling behavior (the DM) with the song control system, especially the HVC and RA [Wild, 1997]. Both the DM and RA project to the same suite of motor neurons controlling vocal production [Wild, 1997], and the RA also projects to the DM, suggesting that the DM could influence song production while the song control system could, in turn, modify calls. As noted, the HVC and RA are necessary for the production of learned vocalizations, including the learned components of calls [Simpson and Vicario, 1990; Fukushima and Aoki, 2000]. The DM is currently not seen as being implicated in song production, though this may simply reflect a lack of data [Wild, 1997]. Studies of song production routinely fail to look for contributions of the DM to song and, conversely, it is unclear if the HVC and RA influence call production (especially complex calls) beyond providing an individual signature, as in estrildid finches [Simpson and Vicario, 1990; Fukushima and Aoki, 2000]. Call or song control regions could be expected to play a role in controlling information-bearing vocal variation, and different vocal parameters could be controlled by different regions.

FOS Labeling in the HVC Related to Meaningful

Call Parameters

With respect to the chick-a-dee call, we found that the number of FOS-labeled cells in the HVC varied with the production of $\mathrm{D}$ notes by individuals, suggesting a role in vocal production beyond song for the HVC. This role may depend on whether D notes are learned, but it is unclear if learning occurs; D notes of a flock increase in similarity over weeks, but no definitive learning study has addressed this [Mammen and Nowicki, 1981; Nowicki, 1989; Clemmons and Howitz, 1990; Hughes et al., 1998]. One explanation for our findings is that the HVC provides an individual signature to otherwise unlearned $\mathrm{D}$ notes in chickadees, as in estrildid finches [Simpson and Vicario, 1990; Fukushima and Aoki, 2002], resulting in more HVC activity as more D notes are produced. However, if modulations to D notes or the notes themselves are learned, the 'song' system would presumably be responsible for their production generally, which would also generate a relationship between HVC labeling and D-note production.

FOS Labeling in the DM Related to Call Structure

The role of the DM in the production of the chick-adee call contrasted with that of the HVC. Rather than correlating with the number of notes produced, the number of FOS-labeled cells in the DM related to the quality of these notes, though most of these measures have not been shown to transmit information. More labeling was associated with lower-pitched, noisier calls of higher bandwidth. Few studies have analyzed exactly how the DM relates to vocal production. Electrostimulation of the DM elicits alarm call and contact call production in a number of species [Brown, 1965a; Potash, 1970; Brown, 1971; Armitage and Seller, 1981; Seller, 1981], but few studies have examined the immunocytological properties of this nucleus [Ball et al., 1989a], nor how such properties relate to vocal output. We identified relationships to actual call structure and possibly syntax (marginally significant relationships with the total number of notes) as opposed to overall levels of call production (call rate). The POM projecting to the DM is the only known direct projection from the POM to a song production pathway [Riters and Alger, 2004]. Interestingly, for both entropy and peak frequency, patterns of FOS labeling in the DM were opposite those in the POM. Further work should investigate the links between the two, with respect to the production of different vocalizations and the variation within single vocal types.

We interpret the relationship of the HVC and DM to call parameters as one of sensorimotor control, given previous understandings of the function of these regions [Ziegler and Marler, 2008]. As noted, these regions project directly to a range of premotor nuclei involved in 
lung, mouth and syrinx control [Wild, 1997; Wild et al., 1997], and activity in these areas probably relates to structural aspects of production [Vu et al., 1994]. The HVC, RA and DM are not likely to be directly responsible for imbuing vocalizations with affective content; they do not process contextual information, although the HVC may receive some information from the auditory system [Kelley and Nottebohm, 1979; Nottebohm et al., 1982]. The POM, LS and PVN, however, do not project directly to vocal premotor neurons [Swanson and Sawchenko, 1983; Balthazart and Absil, 1997; Montagnese et al., 2004; Riters and Alger, 2004]. We propose that immunolabeling relationships with call structure in these areas reflect an affective signal being sent to the sensorimotor regions (including the call and song control systems), perhaps modulating the outputs of these regions and thus the final vocalization.

Call Production and Labeling Patterns Vary between the Sexes

The sex differences in both the mean total notes and mean number of D notes per call are intriguing. Interestingly, we found differences in production only when statistically accounting for the number of labeled cells in several examined regions. Males produced both more notes on average, and more $\mathrm{D}$ notes, for a given level of FOS labeling (table 1). This suggests that observed levels of call production did not actually differ between the sexes, but that different relationships between call production and neural activity exist for each sex. Sex differences in neurochemistry have been identified in the DM, including in $\alpha_{2}$-adrenergic receptors [Ball et al., 1989b] and in estrogen receptors [Voigt et al., 2009], suggesting that the DM could influence sex differences in call production. Sex differences in chick-a-dee call production in this species are not well documented; both studies that looked at differences in the number of notes were unable to determine the sex [Baker and Becker, 2002; Templeton et al., 2005].

\section{Conclusions}

Our results are consistent with the hypothesis that the POM and LS are components of a candidate neural circuit that supplies threat level information to sensorimotor regions governing vocal production, influencing antipredator calls. The logic here is that some call measures have previously been demonstrated to vary with the threat level, and that a variation in vocal response to a stimulus would reflect a variation in how subjects assessed the singular threat we presented in this study. Assessment by the subjects could vary for a number of reasons, depending on health, experience with predators or other factors. Individual birds could also differ in their assessment of the benefits of communication, depending on their current social status or relationships or the costs of communicating. It is also possible that the variation seen in the 2 measures applied here (i.e. behavioral and neural) are related by some unmeasured explanatory factor. Manipulation of a perceived threat, perhaps by comparing subjects that had been habituated to a predator or not, would allow this hypothesis to be tested.

The control of vocal variation, especially in nonsong vocalizations, has been poorly understood [Marler, 2004b]. These data suggest that the brain regions involved in social behavior, in particular the POM and LS, may integrate with those regions controlling calls (DM) and song (HVC) to regulate call structure in a potentially meaningful fashion, suggesting the hypothesis that these areas form a candidate neural circuit for controlling the variation in alarm calls. Our data demonstrate that multiple regions may influence call production within a single context, and that regions governing song production could be involved in a meaningful variation in calls. Additionally, they suggest testable hypotheses for the regulation of meaningful vocal variation, such as changes in call rate and structure. Future work should examine neural differences across functionally distinct call types. Lesions on social brain regions and their effects on call production can also shed light on understanding how information is transmitted and how the brain controls context-dependent vocal production. We suggest that regions involved in social behavior interact to determine the contextually appropriate response, and transmit information to sensorimotor control systems, in this case vocal control regions, which then modulate the structural output to reflect, in this case, a perceived threat.

\section{Acknowledgements}

This work was supported by an NIMH grant, R01 MH080225, to L.V.R. We thank Sharon Stevenson for technical assistance, Bill Feeny for illustrations and Chris Elliot for animal care. 


\section{References}

-Alger SJ, Maasch SN, Riters LV (2009): Lesions to the medial preoptic nucleus affect immediate early gene immunolabeling in brain regions involved in song control and social behavior in male European starlings. Eur J Neurosci 29:970-982.

Alger SJ, Riters LV (2006): Lesions to the medial preoptic nucleus differentially affect singing and nest box-directed behaviors within and outside of the breeding season in European starlings (Sturnus vulgaris). Behav Neurosci 120:1326-1336.

-Appeltants D, Absil P, Balthazart J, Ball GF (2000): Identification of the origin of catecholaminergic inputs to $\mathrm{HVc}$ in canaries by retrograde tract tracing combined with tyrosine hydroxylase immunocytochemistry. J Chem Neuroanat 18:117-133.

Appeltants D, Ball GF, Balthazart J (2002): The origin of catecholaminergic inputs to the song control nucleus RA in canaries. Neuroreport 13:649-653.

- Armitage SE, Seller TJ (1981): Midbrain regions involved in call production of Japanese quail. Cell Mol Life Sci 37:847-848.

Baker MC, Becker AM (2002): Mobbing calls of black-capped chickadees: effects of urgency on call production. Wilson Bull 114:510-516.

- Ball GF, Castelino CB, Maney DL, Appeltants D, Balthazart J (2003): The activation of birdsong by testosterone - multiple sites of action and role of ascending catecholamine projections. Ann NY Acad Sci 1007:211-231.

Ball GF, Foidart A, Balthazart J (1989a): A dorsomedial subdivision within the nucleus intercollicularis identified in the Japanese quail Coturnix coturnix japonica by means of $\alpha_{2}$-adrenergic receptor autoradiography and estrogen receptor immunohistochemistry. Cell Tissue Res 257:123-128.

-Ball GF, Nock B, Mcewen BS, Balthazart J (1989b): Distribution of alpha-2-adrenergic receptors in the brain of the Japanese quail as determined by quantitative autoradiography - implications for the control of sexually dimorphic reproductive processes. Brain Res 491:68-79.

Balthazart J, Absil P (1997): Identification of catecholaminergic inputs to and outputs from aromatase-containing brain areas of the Japanese quail by tract tracing combined with tyrosine hydroxylase immunocytochemistry. J Comp Neurol 382:401-428.

Bradbury JW, Vehrencamp SL (1998): Principles of Animal Communication. Sunderland, Sinauer.

Brenowitz EA, Beecher MD (2005): Song learning in birds: diversity and plasticity, opportunities and challenges. Trends Neurosci 28 : 127-132.

Brown JL (1965a): Vocalization evoked from the optic lobe of a songbird. Science 149:10021003.
Brown JL (1965b): Loss of vocalization caused by lesions in nucleus mesencephalicus lateralis of redwinged blackbird. Am Zool 5:693.

Brown JL (1971): An exploratory study of vocalization areas in the brain of the redwinged blackbird (Agelaius phoeniceus). Behaviour 39:91-127.

Brown JL (1973): Behavior elicited by electrical stimulation of the brain of the Steller's jay. Condor 75:1-16.

Caro T (2005): Antipredator Defenses in Birds and Mammals. Chicago, University of Chicago Press.

Cheney DL, Seyfarth RM (1985): Vervet monkey alarm calls: manipulation through shared information? Behaviour 94:150-166.

Clemmons J, Howitz JL (1990): Development of early vocalizations and the chick-a-dee call in the black-capped chickadee, Parus atricapillus. Ethology 86:203-223.

Courter JR, Ritchison G (2010): Alarm calls of tufted titmice convey information about predator size and threat. Behav Ecol 21:936942.

Curio E (1978): The adaptive significance of avian mobbing. I. Teleonomic hypotheses and predictions. Z Tierpsychol 48:175-183.

Day HEW, Masini CV, Campeau S (2004): The pattern of brain c-Fos mRNA induced by a component of fox odor, 2,5-dihydro-2,4,5trimethylthiazoline (TMT), in rats, suggests both systemic and processive stress characteristics. Brain Res 1025:139-151.

-Dobson H, Ghuman S, Prabhakar S, Smith R (2003): A conceptual model of the influence of stress on female reproduction. Reproduction 125:151-163.

Dubbeldam JL, den Boer-Visser AM (2002): The central mesencephalic grey in birds: nucleus intercollicularis and substantia grisea centralis. Brain Res Bull 57:349-352.

Ellis JMS (2008): Which call parameters signal threat to conspecifics in white-throated magpie-jay mobbing calls? Ethology 114:154-163.

Ficken MS, Ficken RW, Witkin SR (1978): Vocal repertoire of the black-capped chickadee. Auk 95:34-48

Fukushima Y, Aoki K (2000): The role of the dorsomedial nucleus (DM) of intercollicular complex with regard to sexual difference of distance calls in Bengalese finches. Zoolog Sci 17:1231-1238.

Fukushima Y, Aoki K (2002): Neural function of the mesencephalic dorsomedial nucleus (DM) on distance call production in Bengalese finches. Zoolog Sci 19:393-402.

-Gammie SC (2005): Current models and future directions for understanding the neural circuitries of maternal behaviors in rodents. Behav Cogn Neurosci Rev 4:119-135.

Goodson JL (1998): Territorial aggression and dawn song are modulated by septal vasotocin and vasoactive intestinal polypeptide in male field sparrows (Spizella pusilla). Horm Behav 34:67-77.
Goodson JL (2005): The vertebrate social behavior network: evolutionary themes and variations. Horm Behav 48:11-22.

Goodson JL, Eibach R, Sakata J, Adkins-Regan E (1999): Effect of septal lesions on male song and aggression in the colonial zebra finch (Taeniopygia guttata) and the territorial field sparrow (Spizella pusilla). Behav Brain Res 98:167-180.

Goodson JL, Evans AK (2004): Neural responses to territorial challenge and nonsocial stress in male song sparrows: segregation, integration, and modulation by a vasopressin vl antagonist. Horm Behav 46:371-381.

- Goodson JL, Evans AK, Lindberg L, Allen CD (2005): Neuro-evolutionary patterning of sociality. Proc Biol Sci 272:227-235.

-Goodson JL, Kabelik D, Kelly AM, Rinaldi J, Klatt JD (2009): Midbrain dopamine neurons reflect affiliation phenotypes in finches and are tightly coupled to courtship. Proc Natl Acad Sci USA 106:8737-8742.

Griesser M, Ekman J (2005): Nepotistic mobbing behaviour in the Siberian jay, Perisoreus infaustus. Anim Behav 69:345-352.

-Hailman JP, Ficken MS (1986): Combinatorial animal communication with computable syntax - chick-a-dee calling qualifies as language by structural linguistics. Anim Behav 34:1899-1901.

Hailman JP, Ficken MS, Ficken RW (1985): The chick-a-dee calls of Parus atricapillus: a recombinant system of animal communication compared with written English. Semiotica 56:191-224.

-Hailman JP, Ficken MS, Ficken RW (1987): Constraints on the structure of combinatorial chick-a-dee calls. Ethology 75:62-80.

- Hara E, Kubikova L, Hessler NA, Jarvis ED (2007): Role of the midbrain dopaminergic system in modulation of vocal brain activation by social context. Eur J Neurosci 25: 3406-3416.

- Heimovics SA, Cornil CA, Ball GF, Riters LV (2009): D1-like dopamine receptor density in nuclei involved in social behavior correlates with song in a context-dependent fashion in male European starlings. Neuroscience 159: 962-973.

- Heimovics SA, Riters LV (2005): Immediate early gene activity in song control nuclei and brain areas regulating motivation relates positively to singing behavior during, but not outside of, a breeding context. J Neurobiol 65:207-224

Heimovics SA, Riters LV (2006): Breeding-context-dependent relationships between song and c-Fos labeling within social behavior brain regions in male European starlings (Sturnus vulgaris). Horm Behav 50:726-735. 
Heimovics SA, Riters LV (2007): ZENK labeling within social behavior brain regions reveals breeding context-dependent patterns of neural activity associated with song in male European starlings (Sturnus vulgaris). Behav Brain Res 176:333-343.

- Herman JP, Ostrander MM, Mueller NK, Figueiredo H (2005): Limbic system mechanisms of stress regulation: hypothalamo-pituitary-adrenocortical axis. Prog Neuropsychopharmacol Biol Psychiatry 29:1201-1213.

Huang YC, Hessler NA (2008): Social modulation during songbird courtship potentiates midbrain dopaminergic neurons. PLoS One 3:e3281.

Hughes M, Nowicki S, Lohr B (1998): Call learning in black-capped chickadees (Parus atricapillus): the role of experience in the development of 'chick-a-dee' calls. Ethology 104: 232.

- Hull EM, Lorrain DS, Du J, Matuszewich L, Lumley LA, Putnam SK, Moses J (1999): Hormone-neurotransmitter interactions in the control of sexual behavior. Behav Brain Res 105:105-116.

Illes AE, Hall ML, Vehrencamp SL (2006): Vocal performance influences male receiver response in the banded wren. Proc Biol Sci 273: 1907-1912.

Kelley DB, Nottebohm F (1979): Projections of a telencephalic auditory nucleus-field-l in canary. J Comp Neurol 183:455-469.

Liu WC, Wada K, Nottebohm F (2009): Variable food begging calls are harbingers of vocal learning. PLoS One 4:e5929.

Lynch KS, Diekamp B, Ball GF (2008): Catecholaminergic cell groups and vocal communication in male songbirds. Physiol Behav 93: 870-876.

Maklakov AA (2002): Snake-directed mobbing in a cooperative breeder: anti-predator behavior or self-advertisement for the formation of dispersal coalitions? Behav Ecol Sociobiol 52:372-378.

Mammen DL, Nowicki S (1981): Individual differences and within-flock convergence in chickadee calls. Behav Ecol Sociobiol 9:179186.

Maney DL, Ball GF (2003): Fos-like immunoreactivity in catecholaminergic brain nuclei after territorial behavior in free-living song sparrows. J Neurobiol 56:163-170.

Manser MB (2001): The acoustic structure of suricates' alarm calls varies with predator type and the level of response urgency. Proc Biol Sci 268:2315-2324.

-Manser MB, Bell MB, Fletcher LB (2001): The information that receivers extract from alarm calls in suricates. Proc Biol Sci 268: 2485-2491.

-Marler P (1967): Animal communication signals. Science 157:769-774.

-Marler P (2004a): Bird calls: their potential for behavioral neurobiology. Ann NY Acad Sci 1016:31-44.
Marler P (2004b): Bird calls: a cornucopia for communication; in Marler P, Slabbekoorn H, (eds): Nature's Music: The Science of Birdsong. London, Elsevier Academic Press.

-Montagnese CM, Székely AD, Ádám Á, Csillag A (2004): Efferent connections of septal nuclei of the domestic chick (Gallus domesticus): an anterograde pathway tracing study with a bearing on functional circuits. J Comp Neurol 469:437-456.

Mooney R (2009): Neurobiology of song learning. Curr Opin Neurobiol 19:654-660.

Moran MD (2003): Arguments for rejecting the sequential Bonferroni in ecological studies. Oikos 100:403-405.

Nakagawa S (2004): A farewell to Bonferroni: the problems of low statistical power and publication bias. Behav Ecol 15:1044-1045.

-Newman SW (1999): The medial extended amygdala in male reproductive behavior a node in the mammalian social behavior network. Ann NY Acad Sci 877:242-257.

Nottebohm F, Kelley DB, Paton JA (1982): Connections of vocal control nuclei in the canary telencephalon. J Comp Neurol 207:344-357.

Nowicki S (1989): Vocal plasticity in captive black-capped chickadees - the acoustic basis and rate of call convergence. Anim Behav 37: $64-73$.

Person AL, Gale SD, Farries MA, Perkel DJ (2008): Organization of the songbird basal ganglia, including area X. J Comp Neurol 508:840-866.

Potash LM (1970): Vocalizations elicited by electrical brain stimulation in Coturnix coturnix japonica. Behaviour 36:149-167.

- Puelles L, Robles C, Martínez-de-la-Torre M, Martínez S (1994): New subdivision schema for the avian torus semicircularis: neurochemical maps in the chick. J Comp Neurol 340:98-125.

Riters LV, Alger SJ (2004): Neuroanatomical evidence for indirect connections between the medial preoptic nucleus and the song control system: possible neural substrates for sexually motivated song. Cell Tissue Res 316:3544

Riters LV, Teague DP, Schroeder MB, Cummings SE (2004): Vocal production in different social contexts relates to variation in immediate early gene immunoreactivity within and outside of the song control system. Behav Brain Res 155:307-318.

- Rivera-Gutierrez HF, Pinxten R, Eens M (2010) Multiple signals for multiple messages: great tit, Parus major, song signals, age and survival. Anim Behav 80:451-459.

- Seller TJ (1980): Midbrain regions involved in call production in Java sparrows. Behav Brain Res 1:257-265.

- Seller TJ (1981): Midbrain vocalization centres in birds. Trends Neurosci 4:301-303.

-Sherman PW (1977): Nepotism and the evolution of alarm calls. Science 197:1246-1253.

- Simpson HB, Vicario DS (1990): Brain pathways for learned and unlearned vocalizations differ in zebra finches. J Neurosci 10:1541-1556.
Smith SM (1991): The Black-Capped Chickadee. Ithaca, Cornell University Press.

-Sturdy CB, Phillmore LS, Weisman RG (2000): Call-note discriminations in black-capped chickadees (Poecile atricapillus). J Comp Psychol 114:357-364.

-Swanson LW, Sawchenko PE (1983): Hypothalamic integration: organization of the paraventricular and supraoptic nuclei. Annu Rev Neurosci 6:269-324.

-Templeton CN, Greene E, Davis K (2005): Allometry of alarm calls: black-capped chickadees encode information about predator size. Science 308:1934-1937.

Vehrencamp SL (2000): Handicap, index and conventional signal elements of bird song; in Espmark Y, Amundsen T, Rosenqvist G (eds): Animal Signals: Signalling and Signal Design in Animal Communication. Trondheim, Tapir Academic Press, pp 277-300.

-Vicario DS (2004): Using learned calls to study sensory-motor integration in songbirds. Ann NY Acad Sci 1016:246-262.

-Vicario DS, Simpson HB (1995): Electrical stimulation in forebrain nuclei elicits learned vocal patterns in songbirds. J Neurophysiol 73: 2602-2607.

Voigt C, Ball GF, Balthazart J (2009): Sex differences in the expression of sex steroid receptor mRNA in the quail brain. J Neuroendocrinol 21:1045-1062.

-Vu E, Mazurek M, Kuo Y (1994): Identification of a forebrain motor programming network for the learned song of zebra finches. J Neurosci 14:6924-6934.

-Welbergen JA, Davies NB (2008): Reed warblers discriminate cuckoos from sparrowhawks with graded alarm signals that attract mates and neighbours. Anim Behav 76:811-822.

Wild JM (1997): Neural pathways for the control of birdsong production. J Neurobiol 33:653670.

Wild JM (2004): Functional neuroanatomy of the sensorimotor control of singing. Ann NY Acad Sci 1016:438-462.

Wild JM, Li DF, Eagleton C (1997): Projections of the dorsomedial nucleus of the intercollicular complex (DM) in relation to respiratory-vocal nuclei in the brainstem of pigeon (Columba livia) and zebra finch (Taeniopygia guttata). J Comp Neurol 377:392-413.

-Woods JK, Deviche P, Corbitt C (2010): Opioid receptor densities analyzed across seasons in the POM and VTA of the dark-eyed junco, Junco hyemalis. J Chem Neuroanat 40:123129.

Ziegler HP, Marler P (eds) (2008): Neuroscience of Birdsong. Cambridge, Cambridge University Press.

Zuberbühler K (2000): Referential labelling in Diana monkeys. Anim Behav 59:917-927.

Zuberbühler K (2001): Predator-specific alarm calls in Campbell's monkeys, Cercopithecus campbelli. Behav Ecol Sociobiol 50:414-422. 